\title{
Scaphoid Fractures below the Age of 10: Case Series and Review of the Literature
}

\author{
Rachana Tataria, MCh, DNB ${ }^{1}$ Jeannette Ting, MBBS, FRACS ${ }^{2}$ Andrea Jester, MD, FRCS ${ }^{1}$ \\ Tommy R. Lindau, MD, $\mathrm{PhD}^{3}$ Kerstin Oestreich, MD, MSc ${ }^{1}$
}

${ }^{1}$ Hand and Upper Limb Service, Department of Plastic Surgery, Birmingham

Women and Children's Hospital, Birmingham, United Kingdom

2 Department of Plastic \& Reconstructive Surgery, Monash Children's

Hospital, Clayton, Victoria, Australia

3 Pulvertaft Hand Centre, Derby, United Kingdom

Address for correspondence Kerstin Oestreich, MD, MSc, Hand and Upper Limb Service, Department of Plastic Surgery, Birmingham Women and Children's Hospital, Steel house Lane, Birmingham B4 $6 \mathrm{NH}$, United Kingdom (e-mail: kerstin.oestreich@nhs.net).

J Wrist Surg 2020;9:458-464.

\begin{abstract}
Background Scaphoid fractures are relatively uncommon in children, especially below the age of 10 due to the ossification of the scaphoid bone, which starts around 4 to 6 years of age and continues until 13 to 15 years of age, where pediatric scaphoid fractures peak. This makes the diagnoses challenging in this age group.

Methods The primary aim of this study was to analyze prospectively collected data in managing scaphoid fractures. All cases in children up to the age of 10 years, treated in a tertiary pediatric hand and upper limb from January 2014 to June 2018 were included. Parameters studied were patient demographics, clinical presentation, mechanism of injury, investigations, type of fracture, associated injuries, treatment offered, outcomes and complications. The secondary aim was to review the literature due to the limited knowledge about these fractures in these low age groups.

Results A total of 23 patients with documented scaphoid fractures in children up to the age of 10 years were found. Final diagnosis in all these patients was done with magnetic resonance imaging (MRI). The mean age was 9.8 years, with female preponderance. Scaphoid waist was the most common location. Five patients had associated fractures of the capitate and one patient had associated second metacarpal base fracture. All patients were managed nonoperatively. The average time of immobilization was 6.6 weeks (range: $4-10$ weeks). A majority of patients had minor symptoms after the fracture, most likely due to the immobilization time.

Keywords

- scaphoid

- fracture

- pediatric

- children

Conclusion Scaphoid fractures are rare in the pediatric population up to the age of 10 . MRI is most often needed to confirm diagnosis. Nonoperative management of most scaphoid fractures in this age group is safe and feasible with no significant long-term morbidity. Surgical management of scaphoid fractures might be required in very selected cases.

Level of Evidence This is a Level IV study.
\end{abstract}

Carpal fractures are uncommon in the pediatric population, of which the scaphoid is the most common carpal bone involved. ${ }^{1-4}$ With a peak frequency between the ages of 12 and 15 years, they are a rarely found under the age of 10 years. ${ }^{3-5}$

received

March 6, 2020

accepted

May 21, 2020

published online

July 15,2020
Since the last decade the incidence of scaphoid fractures in the pediatric population is increasing. ${ }^{6-8}$ Active participation of children in competitive sports is considered the cause for the increased incidence of sports-related hand and wrist
Copyright $\odot 2020$ by Thieme Medical Publishers, Inc., 333 Seventh Avenue, New York, NY 10001, USA Tel: +1(212) 760-0888
DOI https://doi.org/ 10.1055/s-0040-1713800. ISSN 2163-3916. 
injuries, ${ }^{9-11}$ although improved awareness and imaging may contribute to the increase detection of these injuries.

Patterns of scaphoid fractures in children vary from those found in adults. ${ }^{2,12}$ There is a paucity of data in the literature on fractures in children up to the age of 10 years despite the increasing incidence and increased use of advanced imaging modalities to diagnose those injuries. ${ }^{13,14}$ In fact, there is only one early paper addressing this particular age group. ${ }^{15}$

Scaphoid fractures in children, as opposed to adults, are less prone to displacement, frequently being incomplete and heal well on conservative management. ${ }^{1,2,5,16}$ Diagnosing scaphoid fractures in children can be difficult due to failure to elicit classical clinical signs. ${ }^{1,14,17}$ A standard wrist X-ray cannot detect fractures in the nonossified elements of the bone which is frequent in young children. ${ }^{3}$ Distal pole fractures of the scaphoid are the most frequent in children as compared with the waist fractures in adults, most likely due to the early ossification in the distal part of the bone., 5,18 Scaphoid fractures in children when detected after trauma and managed as such, usually heal well without any major complications. ${ }^{19,20}$ We have reviewed the data on our series of patients with scaphoid fracture up to 10 years of age who were managed at a tertiary pediatric hand and upper limb trauma center and in addition reviewed the limited literature.

\section{Methods}

The primary aim of this study was to look into a prospective database that was set up in January 2014 to fully assess all carpal injuries in children of all ages ( - Fig. 1). From this database we identified patients with scaphoid fractures up to the age of 10 years up until June 2018 ( - Figs. 2 and 3). The data was analyzed regarding demographic distribution, affected side, mechanism of injury, clinical presentation, investigations, type of fracture (proximal, waist, or distal), associated injuries, number of follow-ups, type of fracture management, and final outcomes with complications.

At presentation, all 23 patients had significant clinical findings out of which 20 had pain, 13 had marked swelling, and 9 had reduced range of wrist movement. On clinical examination, 12 had positive telescoping test (axial load through the thumb) at the time of initial consultation.

All patients had wrist posterior-anterior (PA) and lateral X-ray views initially (-Figs. $\mathbf{2 A}$ and $\mathbf{3 A}$ ). Only one of the

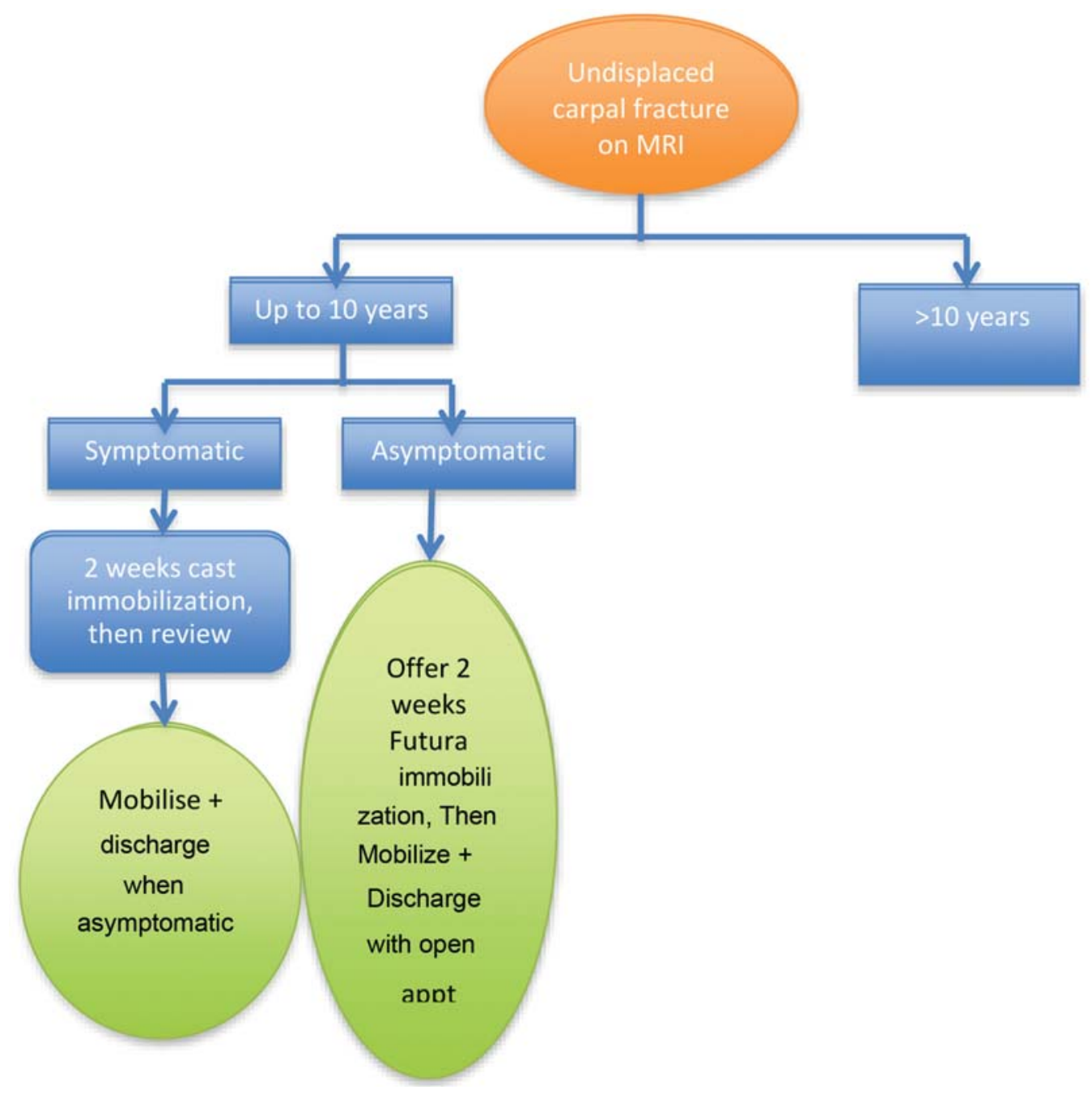

Fig. 1 A prospective database was set up in January 2014 to fully assess all carpal injuries in children of all ages. This subgroup of the algorithm shows the management of scaphoid fractures. 


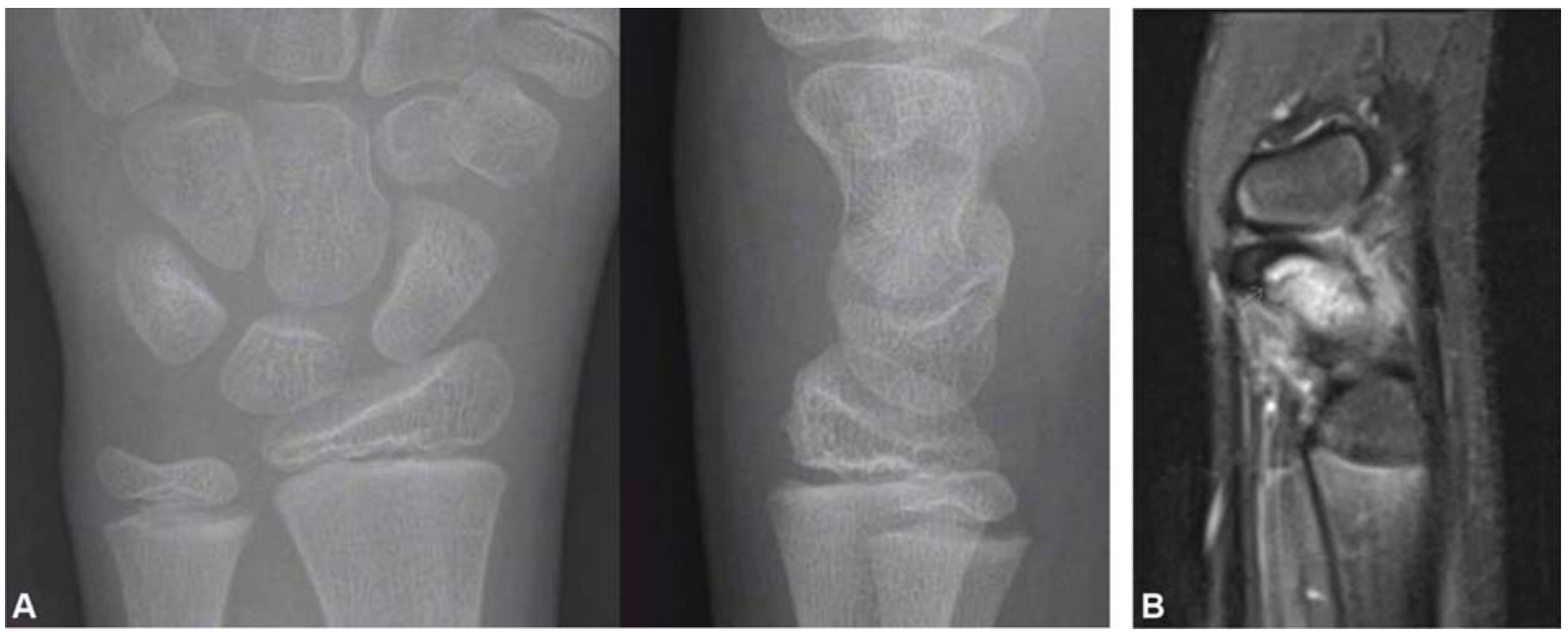

Fig. 2 A 9-year-old boy, fall on outstretched hand while playing in the garden. (A) Radiograph (posterior-anterior and lateral) of left wrist, distal pole scaphoid fracture not visible on a plain film. (B) MRI (T1 TSE, sagittal view) image of distal pole scaphoid fracture with cortical breach (arrow). MRI, magnetic resonance imaging; TSE, turbo spin echo.

X-rays showed a definite distal pole scaphoid fracture. Due to the amount of clinically suspicious findings, the patients were all immobilized into a scaphoid cast or wrist splint including thumb. All patients, who continued to be symptomatic 1 week after trauma, had a magnetic resonance imaging (MRI) (-Figs. 2 and 3). Computed tomography (CT) was not used due to the amount of radiation exposed to as per national guidelines for imaging in children.

All patients included had radiologically proven scaphoid fractures on MRI. All patients were reviewed after MRI. Further follow-up with evaluation of symptoms and length of immobilization was documented. A long-term open appointment was offered to rule out any chronic untoward sequelae.

Patients with incomplete medical records and those with inconclusive imaging findings were excluded from the study. Also, patients who were treated for scaphoid fractures but where there was a delay in imaging were also excluded.

The second aim of the study was to review the literature due to the limited knowledge about these fractures in this young age group. We looked at Cochrane trials, Medline, Embase, and Cinahl in May 2018. The keywords used to search were "scaphoid," "fracture," "pediatric." The search yielded a total of 17 Cochrane trials registered, 98 articles in
Medline, 99 in Embase, and 116 in Cinahl. We finally extracted 142 papers once duplicates had been removed. We only found five studies relevant to pediatric scaphoid fractures in this age group and analyzed them with respect to demographics and management. We did not do a systematic review as this paper is primarily a case series.

\section{Results}

\section{Demographics}

Our case series of scaphoid fractures included 23 patients up to the age of 10 years over a period from January 2014 to June 2018. Although this study was not set up to be an epidemiological study, it suggests that the incidence is six per year in a tertiary pediatric hand and upper limb trauma center. The mean age of the group was 9.8 years, the youngest being 7 years. Females were predominantly affected ( 14 girls and 9 boys). Most commonly, the injury was due to a fall on the outstretched hand, of which 11 children sustained fractures during sports activities, six due to other activities/ play, three due to fall from a bike and remaining three were unspecified. Seventeen patients had their left side affected as compared with six subjects who had fractured their right scaphoid.
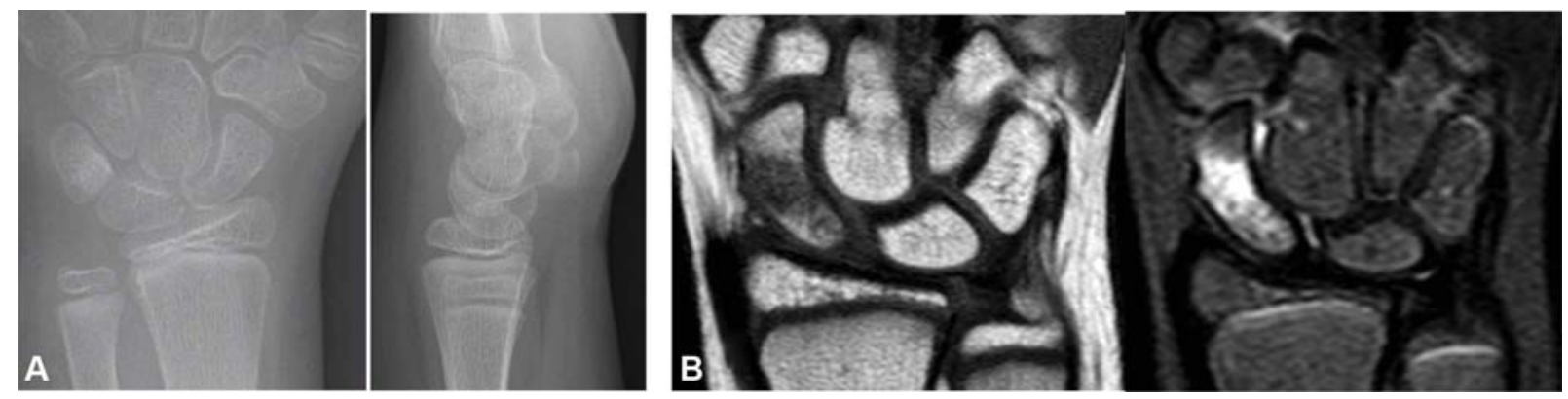

Fig. 3 A 9-year-old girl with a fall on flexed left wrist. (A) Radiograph (posterior-anterior and lateral) of left wrist. A distal pole scaphoid fracture not visible on a plain film. (B) MRI (T1W TSE and STIR_long_TE, sagittal views) image of waist fracture left scaphoid. MRI, magnetic resonance imaging; TSE, turbo spin echo. 
Pre-existing comorbidities were found in one boy with associated generalized hypermobility. Another boy suffered from hemophilia (von Willebrand's disease) as a comorbidity affecting the fracture outcome due to increased bruising and swelling.

\section{Clinical Outcomes}

The patients had an average of four visits for consultation and review before discharge. The average follow-up was 7.4 weeks.

A mean duration of 6.7 weeks (range: 4-10 weeks) of immobilization was recorded for all patients. The duration of immobilization was guided by clinical symptoms, not by further imaging as in adults. The average duration of immobilization with respect to fracture type was 6.4 weeks for distal pole (nine patients) and 6.9 weeks for waist fractures (12 patients). Only one patient with proximal pole fracture in the series required 8 weeks of immobilization.

Patients with associated capitate fractures (five patients) required immobilization with an average of 6.4 weeks (range 4-9 weeks), which was similar in length than the overall average of 6.7 weeks.

None of the patients required surgery.

At the time of discharge 20 of the 23 patients had some minor symptoms; nine had mild pain, six had some stiffness, four had some pain on telescoping test, and one had minor swelling. Seven patients underwent hand therapy for pain and joint stiffness. At discharge a long-term follow-up appointment was offered and none of the patients had persistent symptoms.

\section{Radiology}

All patients had wrist PA and lateral X-ray views initially. MRI imaging was performed in all patients with suspected scaphoid fractures to confirm the diagnosis. The incidence of distal pole (nine patients) and waist fracture (12 patients) seen on MRI was similar, a proximal pole fracture was reported in one patient. One patient had a fracture through both distal pole and the waist of the scaphoid, which may have represented a compound fracture. An associated capitate fracture was present in five patients and one patient had an associated fracture through the base of the second metacarpal.

\section{Review of the Literature}

We reviewed studies relevant to pediatric scaphoid fractures in this young population from the literature search. The papers were analyzed with respect to demographics and management ( $\mathbf{-}$ Table $\mathbf{1}$ ).

Most studies refer to patient groups above the age of 10 , hence comparison is difficult. Immobilization on an average of 4.2 weeks has been reported in a patient group up to 13 years of age (-Table $\mathbf{1}){ }^{21}$ which is considerably shorter than our results of 6.7 weeks for isolated scaphoid fractures. Conservative management is supported by several studies. ${ }^{2,22}$ However, surgical treatment for acute fractures has been used quite often (6/39 patients) in a recent study, where it is unclear in which age group this was done ${ }^{23}$ (-Table 1). Furthermore, nonunions in children, not necessarily in ages below 10 , have

\begin{tabular}{|c|c|c|c|c|c|}
\hline 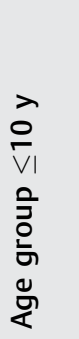 & 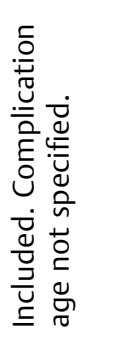 & 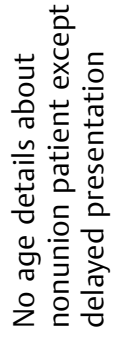 & $\begin{array}{l}\frac{n}{0} \\
\frac{\pi}{0} \\
0 \\
0 \\
0 \\
0 \\
0 \\
z\end{array}$ & 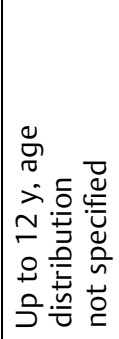 & 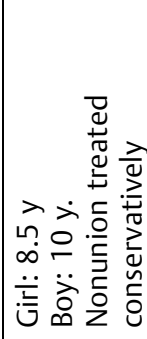 \\
\hline 产 & 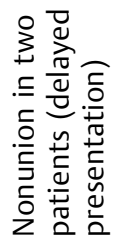 & 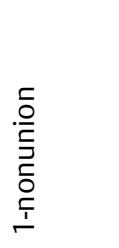 & $\frac{s}{z}$ & 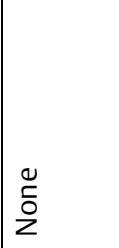 & 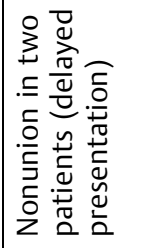 \\
\hline 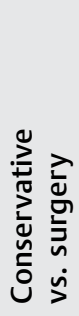 & 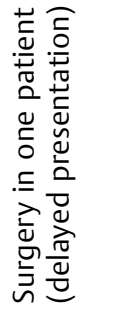 & 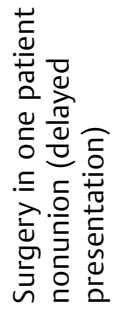 & 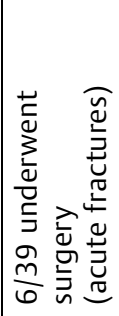 & 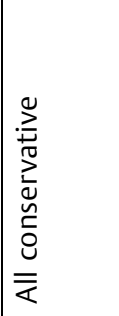 & 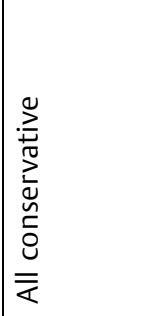 \\
\hline 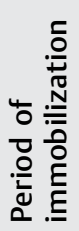 & $\frac{\sigma}{\bar{n}}$ & 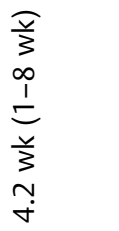 & 1 & I & 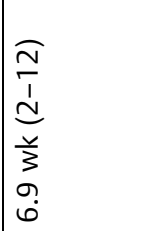 \\
\hline 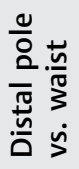 & 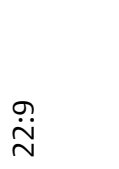 & 号 & $\begin{array}{l}\text { 우 } \\
\text { ă }\end{array}$ & $\stackrel{m}{r}$ & 1 \\
\hline$\stackrel{\square}{\ddot{\Sigma}}$ & 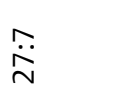 & స̃ & $\begin{array}{l}\stackrel{ \pm}{\sim} \\
\ddot{m}\end{array}$ & $\frac{\Sigma}{z}$ & $\ddot{\ddot{\theta}}$ \\
\hline 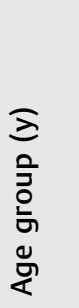 & 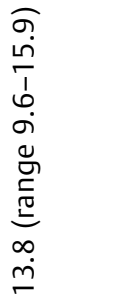 & 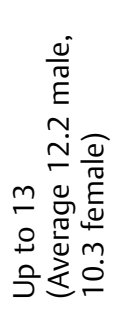 & $\begin{array}{l}\text { In } \\
\stackrel{+}{\leftarrow}\end{array}$ & 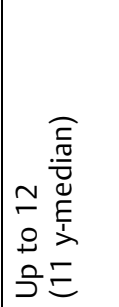 & $\underset{\sim}{\stackrel{\sim}{\sim}}$ \\
\hline$\frac{\frac{0}{n}}{\stackrel{n}{n}} \frac{\stackrel{N}{n}}{n}$ & $\stackrel{\nabla}{m}$ & ம & 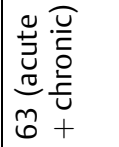 & $\stackrel{m}{r}$ & $\stackrel{m}{\sim}$ \\
\hline 은 & 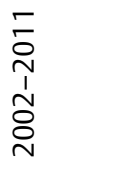 & $\begin{array}{l}\hat{o} \\
0 \\
N \\
1 \\
\tilde{o} \\
0 \\
N\end{array}$ & 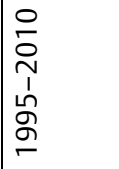 & ํㅗㅇ & $\begin{array}{l}\frac{\hat{\sigma}}{2} \\
\frac{1}{1} \\
\frac{1}{2} \\
\frac{1}{n}\end{array}$ \\
\hline 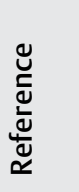 & 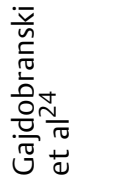 & 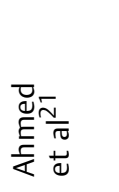 & 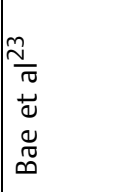 & 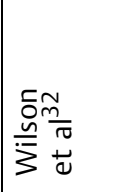 & 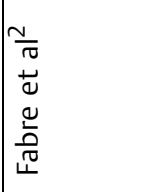 \\
\hline
\end{tabular}


been seen due to delayed presentation for which surgical treatment was necessary ${ }^{21,24}$ ( - Table 1).

\section{Discussion}

The scaphoid is the most frequent carpal bone injured in children. ${ }^{4}$ The incidence of scaphoid fractures is increasing in children probably due to change in pattern of sports, ${ }^{4}$ but increased awareness of this diagnosis in this young population may be another important reason for the increased incidence.

The carpal bones have a set sequence of ossification, starting from the capitate and hamate, then the triquetrum and lunate, followed by scaphoid, trapezium and trapezoid, and lastly the pisiform (-Fig.4). ${ }^{25}$ The ossification of the first metacarpal bone occurs simultaneously with the scaphoid and hence could be an indicator of scaphoid maturity. The ossification process of the scaphoid bone progresses from distal to proximal, begins at 5 to 6 years of age and ceases at approximately 15 years and 3 months in boys and at approximately 13 years and 4 months in girls. ${ }^{20,26,27}$ During this period the scaphoid is almost entirely cartilaginous, which makes the children both less prone to fractures and more difficult to diagnose. The inner osseous nucleus is surrounded by a thick cartilaginous cap during this period as the ossification center grows, that may provide for a cushion and protective layer. ${ }^{8}$ Thereby, it has been postulated that a greater force is required to fracture the growing scaphoid. Hence, scaphoid fractures are difficult to diagnose with Xrays in this age group. This is most likely the reason why there is a relatively higher incidence of failure to diagnose scaphoid fractures in this age group, especially when they are associated with the distal forearm and other wrist injuries. ${ }^{9}$ More importantly, these underlying facts may explain the increased incidence in distal pole fractures that ossifies earlier than the proximal pole and scaphoid fractures in girls who ossify earlier than boys.

Hence, MRI is needed to diagnose scaphoid fractures in this age group. It has been shown that a normal initial MRI is associated with a negative predictive value of $100 \%$ in children with suspected scaphoid fracture. ${ }^{28}$ The majority of the pediatric literature of scaphoid fractures constitutes

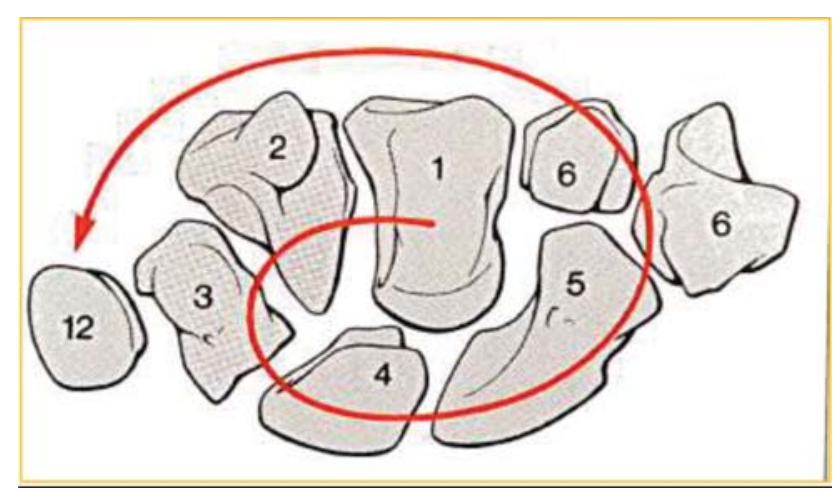

Fig. 4 Ossification spiral of carpal bones (numbers within rule of thumb for ossification of the carpal bone in years). (Adapted from Schmid and Lanz ${ }^{25}$.). those in the age group of 12 to 15 years. We only found one early paper that looked at scaphoid fractures below the age of 10 years, ${ }^{15}$ possibly because these fractures are most often not found with X-rays in this age group therefore being under-diagnosed and under-reported (-Figs. 2 and $\mathbf{3}$ ).

In significant injuries of hand and wrist in children, as well as in adults, a low threshold of suspicion of scaphoid fracture should be kept in mind. ${ }^{29,30}$ In spite of the large cartilaginous cap making the diagnosis of scaphoid fractures difficult in this age group, some authors suggest that a wrist X-ray is always recommended. ${ }^{2,3}$ It is estimated that nearly $37 \%$ of carpal fractures are missed initially due to the nonossified cartilaginous portion of carpal bones. ${ }^{14,29,31}$ The treatment protocol followed in our tertiary pediatric hand and upper limb trauma center is to invariably immobilize the wrist in cases where there are high clinical suspicions of fracture with negative radiography until further imaging rules out or confirms fractures. In this respect, MRI is advantageous to CT due to the absence of radiation with MRI.

We followed-up our patients within 2 weeks from injury, which is supported by the literature. ${ }^{14}$ We then requested MRI to rule out or confirm fracture, which again is supported by the literature ${ }^{32}$ as MRI imaging in children aids in quick diagnosis with early treatment and minimizes the amount of ionizing radiation exposure in children. ${ }^{32}$ It is important to understand that MRI will better evaluate the cartilaginous portion of the growing scaphoid, which may be undetected on CT imaging or plain radiography $2,5,17,29,31,32$ and will also detect associated carpal injuries. ${ }^{2,5,17,29,31,32}$ We understand that an initial MRI is not a practical solution in all centers, due to limitations with access to MRI.

The trend of an epidemiological shift of fracture pattern in children from distal pole (without displacement) to waist and proximal fractures is most likely due to the ossification from distal to proximal. Another factor may be the rising participation in contact and high velocity sport activities and finally due to improved imaging detecting fractures that previously were not identifiable. ${ }^{1-3,5,16,18}$

However, most papers have not differentiated the relationship between this statement and age groups, fracture site, etc. ${ }^{1,2,16,20,22}$ It is well established that the need for immobilization varies with the location of the fracture within the scaphoid. ${ }^{4,19,22}$ More importantly, in contrast to adults where further imaging will confirm fracture union we have to rely on clinical examination in this young age group to decide when mobilization can commence. This is difficult as any signs of tenderness or true pain will extend the immobilization in these young children. We found that the longest time of immobilization was needed for proximal pole fractures ( 8 weeks in one patient) and/or in waist fractures (mean duration of immobilization 6.9 weeks in 12 patients). These fractures, as well as combined injuries, are only detectable with MRI due to the cartilaginous cap. Hence, we strongly advise that MRI should be the cornerstone while investigating injuries in children in general and in children below the age of 10 in particular.

The literature supports our findings that all, or at least most, fractures heal well with nonoperative management 
although our results imply a relatively large group where some minor symptoms persist after the normal healing period. ${ }^{1,2,16,20,22}$ These symptoms of discomfort may in fact be caused by the relatively long immobilization time we report, which in turn is long as these young children are difficult to safely examine to confirm clinically healed fractures as further imaging should be avoided in this age group.

\section{Limitations}

We agree that the sample size in our case series does not include all the patients with scaphoid fractures treated in the period as cases with incomplete medical records and inconclusive or delayed imaging findings were excluded from the study. Also, some subjects were empirically treated as scaphoid fractures on the basis of clinical suspicion due to delay in getting MRI imaging. Furthermore, as we represent a tertiary pediatric hand and upper limb trauma center, we cannot conclude that our stated incidence of six patients per year is valid as there may have been patients within our tertiary catchment area that were never referred to us. We do, however, think that scaphoid fractures in this age group are not as rare as previously stated.

We also conclude that the literature review gives limited accuracy for comparison, as often ages are not defined to the younger cohort ( $<10$ years).

\section{Conclusion and Guidelines}

The incidence of scaphoid fractures in the skeletally immature age below 10 years is relatively low, although our findings of six patients per year make it less rare than previously stated. Hence, it is important to have a high suspicion for scaphoid fractures even in the very young. The frequent use of MRI gives an early diagnosis and improved management of all wrist injuries, especially scaphoid fractures. The length of immobilization should be guided by clinical symptoms more than imaging in this age group, although this is a difficult way of truly assessing union. Fractures in this age group seem to heal with adequate immobilization, although surgery is sometimes required if there is a delay in presentation ${ }^{21,24}$ (-Table $\mathbf{1}$ ). To our surprise, we found a relatively large group of children with remaining minor symptoms that may require hand therapy prior to discharge. We suspect that this may have been partly caused by the relatively long immobilization time reported.

Note

The work for the above series was done at Birmingham Children's Hospital, Birmingham, United Kingdom.

Conflict of Interest

None declared.

\section{References}

1 D'Arienzo M. Scaphoid fractures in children. J Hand Surg $[\mathrm{Br}]$ 2002;27(05):424-426
2 Fabre O, De Boeck H, Haentjens P. Fractures and nonunions of the carpal scaphoid in children. Acta Orthop Belg 2001;67(02):121-125

3 Barthel P-Y, Journeau P, Barbary S, et al. Sequelles et reprise chirurgicale des fractures du carpe, des metacarpiens et des doigts chez l'enfant. In: Billy B, Langlais J, Dutoit M, Zambelli PY, eds. Reprises et sequelles en traumatologie de l'enfant. MontpellierParis: Sauramps Medical; 2010:187-200

4 Toh S, Miura H, Arai K, Yasumura M, Wada M, Tsubo K. Scaphoid fractures in children: problems and treatment. J Pediatr Orthop 2003;23(02):216-221

5 Bhatti AN, Griffin SJ, Wenham SJ. Deceptive appearance of a normal variant of scaphoid bone in a teenage patient: a diagnostic challenge. Orthop Rev (Pavia) 2012;4(01):e6

6 Beatty E, Light TR, Belsole RJ, Ogden JA. Wrist and hand skeletal injuries in children. Hand Clin 1990;6(04):723-738

7 Christodoulou AG, Colton CL. Scaphoid fractures in children. J Pediatr Orthop 1986;6(01):37-39

8 Greene MH, Hadied AM, LaMont RL. Scaphoid fractures in children. J Hand Surg Am 1984;9(04):536-541

9 Stanciu C, Dumont A. Changing patterns of scaphoid fractures in adolescents. Can J Surg 1994;37(03):214-216

10 Brudvik C, Hove LM. Childhood fractures in Bergen, Norway: identifying high-risk groups and activities. J Pediatr Orthop 2003;23(05):629-634

11 Dolan M, Waters PM. Fractures and dislocations of the forearm, wrist and hand. In: Green NE, Swiontkowski MF, eds. Skeletal Trauma in Children. Vol. 3. Philadelphia: Saunders Elsevier; 2009:159-207

12 Leslie IJ, Dickson RA. The fractured carpal scaphoid. Natural history and factors influencing outcome. J Bone Joint Surg $\mathrm{Br}$ 1981;63-B(02):225-230

13 Tan YW, Maffulli N. Carpal scaphoid fracture in the skeletally immature: a single centre one-year prospective study. Acta Orthop Belg 2009;75(05):616-622

14 Evenski AJ, Adamczyk MJ, Steiner RP, Morscher MA, Riley PM. Clinically suspected scaphoid fractures in children. J Pediatr Orthop 2009;29(04):352-355

15 Vahvanen V, Westerlund M. Fracture of the carpal scaphoid in children. A clinical and roentgenological study of 108 cases. Acta Orthop Scand 1980;51(06):909-913

16 Wulff RN, Schmidt TL. Carpal fractures in children. J Pediatr Orthop 1998;18(04):462-465

17 Lögters TT, Linhart W, Schubert D, Windolf J, Schädel-Höpfner M. Diagnostic approach for suspected scaphoid fractures in children. Eur J Trauma Emerg Surg 2008;34(02):131-134

18 Hamdi MF, Khelifi A. Operative management of nonunion scaphoid fracture in children: a case report and literature review. Musculoskelet Surg 2011;95(01):49-52

19 Gholson JJ, Bae DS, Zurakowski D, Waters PM. Scaphoid fractures in children and adolescents: contemporary injury patterns and factors influencing time to union. J Bone Joint Surg Am 2011;93 (13):1210-1219

20 Huckstadt T, Klitscher D, Weltzien A, Müller LP, Rommens PM, Schier F. Pediatric fractures of the carpal scaphoid: a retrospective clinical and radiological study. J Pediatr Orthop 2007;27(04):447-450

21 Ahmed I, Ashton F, Tay WK, Porter D. The pediatric fracture of the scaphoid in patients aged 13 years and under: an epidemiological study. J Pediatr Orthop 2014;34(02):150-154

22 Gholson JJ, Waters PM, Zurakowski D, Bae DS. Functional outcomes following treatment of scaphoid fractures in children and adolescents. J Hand Surg Am 2013;38(10):e49

23 Bae DS, Gholson JJ, Zurakowski D, Waters PM. Functional outcomes after treatment of scaphoid fractures in children and adolescents. J Pediatr Orthop 2016;36(01):13-18

24 Gajdobranski D, Zivanović D, Mikov A, et al. Scaphoid fractures in children. Srp Arh Celok Lek 2014;142(7-8):444-449

25 Schmid HM, Lanz U. Entwicklung der Hand. In: Chirurgische Anatomie der Hand. Stuttgart, Germany: Thieme; 2003:5-8 
464 Scaphoid Fractures below the Age of 10: Case Series and Review of the Literature Tataria et al.

26 Stuart HC, Pyle SI, Cornoni J, Reed RB. Onsets, completions and spans of ossification in the 29 bonegrowth centers of the hand and wrist. Pediatrics 1962;29:237-249

27 Hägg U, Taranger J. Skeletal stages of the hand and wrist as indicators of the pubertal growth spurt. Acta Odontol Scand 1980;38(03):187-200

28 Cook PA, Yu JS, Wiand W, Cook AJ II, Coleman CR, Cook AJ. Suspected scaphoid fractures in skeletally immature patients: application of MRI. J Comput Assist Tomogr 1997;21(04):511-515
29 Foley K, Patel S. Fractures of the scaphoid, capitate and triquetrum in a child: a case report. J Orthop Surg (Hong Kong) 2012;20(01):103-104

30 Elhassan BT, Shin AY. Scaphoid fracture in children. Hand Clin 2006;22(01):31-41

31 Anz AW, Bushnell BD, Bynum DK, Chloros GD, Wiesler ER. Pediatric scaphoid fractures. J Am Acad Orthop Surg 2009;17(02):77-87

32 Wilson EB, Beattie TF, Wilkinson AG. Epidemiological review and proposed management of 'scaphoid' injury in children. Eur J Emerg Med 2011;18(01):57-61 